\title{
Experimental measuring procedure for the friction torque in rolling bearings
}

\author{
Tiago Cousseau ${ }^{1, *, \dagger}$, Beatriz Graça ${ }^{1}$, Armando Campos $^{2}$ and Jorge Seabra ${ }^{3}$ \\ ${ }^{1}$ Instituto de Engenharia Mecânica e Gestão Industrial, Porto, Portugal \\ ${ }^{2}$ Instituto Superior de Engenharia, Instituto Politécnico do Porto, Porto, Portugal \\ ${ }^{3}$ Faculdade de Engenharia da Universidade do Porto, Porto, Portugal
}

\begin{abstract}
The reduction of the power loss generated in mechanical transmissions and the use of low friction biodegradable lubricants has been attracting considerable attention in recent times. Therefore, it is necessary to develop methods to test and evaluate the performance of such lubricants and compare them with conventional ones.

In this sense, a Four-Ball Machine was modified allowing the test of rolling bearings. A 51107 thrust ball bearing was used to test two different greases and the corresponding base oils. Friction torque and operating temperatures were continuously monitored to quantify the power loss and the heat evacuation for each lubricant tested. Copyright @ 2010 John Wiley \& Sons, Ltd.
\end{abstract}

Received 26 August 2009; Revised 11 December 2009; Accepted 14 February 2010

KEY WORDS: rolling bearings; friction torque; energy loss; biodegradable greases

\section{INTRODUCTION}

The internal friction torque occurring in rolling bearings is of major concern, since the main function of rolling bearings is to transmit load at very low friction. Thus, the importance of understanding internal friction in rolling bearings becomes relevant when energy saving and bearing performance optimization are required.

There are two major friction sources inside a bearing: the friction occurring in the contact between the rolling elements and rings and the friction due to the lubricant flow between the bearing elements (rings, rolling elements and cage). Both energy loss mechanisms are highly dependent on the grease ability to generate an efficient lubricant film between the bearing surfaces. ${ }^{1}$

Biodegradable greases start to become an option to replace conventional greases in rolling bearing lubrication. Two main reasons explain this: (i) environmental awareness and (ii) the high mechanical and chemical performance of bio-greases. However, the behaviour of biodegradable greases is not yet well known, mainly in terms of rolling bearing wear and power loss. Consequently, new

*Correspondence to: Tiago Cousseau, Instituto de Engenharia Mecânica e Gestão Industrial — INEGI, Rua Dr Roberto Frias, 400, Porto 4200-465, Portugal.

E-mail: tcousseau@inegi.up.pt

Copyright (C) 2010 John Wiley \& Sons, Ltd. 
experimental methods and analytical tools have to be developed to compare the tribological and energetic behaviour of these new biodegradable greases with reference ones.

Many designs of grease tribo-testing equipment have been developed, mainly by bearing and grease manufacturers (Timken, SKF, Hoffmann, etc.). Some are carried out on bench-mounted apparatus and other in actual machines. ${ }^{2}$ The results obtained are normally used to study the friction, wear and properties of the lubricating greases. The most commonly used tests to evaluate the grease specifications were studied and standardized by the American Society for Testing and Materials. ${ }^{3}$ However, new methods are developed and added to give more information about the grease behaviour during lubrication, such as rheological tests.

Several research studies on the grease lubrication mechanisms have been done on single contact configurations where the rolling element ring contact is simulated by a ball on a flat disc. ${ }^{4,5}$ The major advantage of this simple geometry is the possibility to accurately measure film thickness using optical methods. The main drawback is the large difference in timescale between successive over-rolling and the impossibility to simulate the true lubricant flow, the lubricant feed and the loss mechanisms occurring inside the bearing. Moreover, the large centrifugal forces acting on the grease in the bearing cannot be simulated in these instruments. ${ }^{6}$

The main purpose of this paper is to describe the procedures developed and applied to perform a rolling bearing test using a conventional Four-Ball Machine (Cameron-Plint TE 82/7752). The first part of the paper will present the main modifications made on the machine and describes the bearing test procedures developed in order to obtain reliable friction and temperature measurements. An assembly using a 51107 thrust ball bearings is tested as an example. The second part will illustrate the kind of results that can be obtained to study and understand the friction behaviour when different types of greases are used to lubricate rolling bearings.

\section{EXPERIMENTAL ASSEMBLY}

The rolling bearing tests were performed using a modified Four-Ball machine, where the four-ball arrangement was replaced by a rolling bearing assembly, as shown in Figure 1. The example is for a thrust ball bearing. This new assembly was developed to test different types of rolling bearings lubricated with oil or grease.

\section{Rolling bearing assembly}

The mounting phases for each test are the following (see Figure 1).

I. The lower race (3) is fitted on the spacer (2) with J6/p5 tolerance. This set $(3+2)$ is fitted on the bearing house (1) with H6/j5 tolerance. The tight fit used among these parts of the group (A) ensures that there is no relative motion between them.

II. The upper race (5) is mounted on the shaft adapter (6) with P5/j6 tolerance, also to prevent relative motion between them, composing the group (B).

III. To prevent contamination by external particles resulted from the mounting operations (groups A and B), and also to remove the oil film protection of the bearing package, the groups A and B and the rolling elements and cage (4) are washed with solvent in an ultrasonic bath.

IV. Rolling bearing lubrication: 


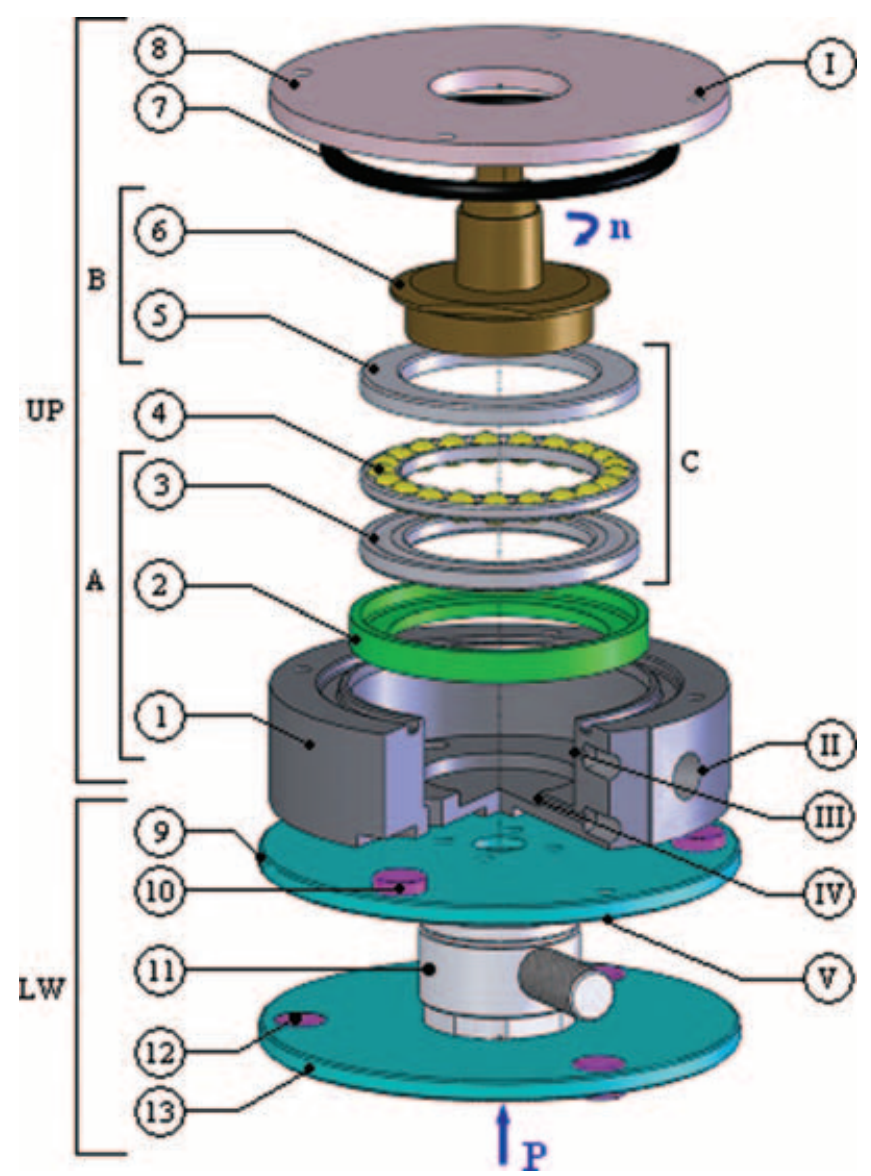

Figure 1. Schematic view of the thrust rolling bearing assembly.

IVa. Bath oil lubrication: The oil level should reach the centre of the lowest rolling element when the bearing is stationary. ${ }^{1}$ For the thrust ball bearing 51107, the oil volume required is approximately $14 \mathrm{ml}$. During this operation the rolling elements and cage (4) are already on the lower race (3) and the thermocouples (III, IV) should be assembled on the bearing house (1), preventing oil leakage through the thermocouple holes.

IVb. Grease lubrication: The grease should be applied by an amount that will replenish the bearing without causing churning and heat generation. As a general rule, when starting up only the bearing should be completely filled, while the free space in the housing should be partly filled with grease. ${ }^{1}$ A pre-defined volume of $2 \mathrm{~cm}^{3}$ was determined by the geometry of the bearing house (3), since the grease excess (for values above $2 \mathrm{~cm}^{3}$ ) between the rolling bearing (C) and bearing house (1) can contribute to the friction torque increase and heat generation. This grease volume fills completely the rolling bearing. 


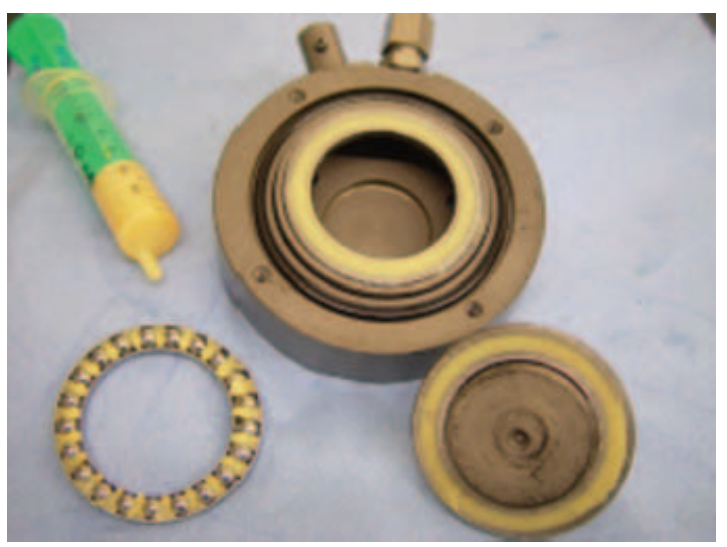

Figure 2. Grease lubrication of the thrust rolling bearing.

The total amount of grease is spread out on the races, on the rolling elements and on the cage with a graduate syringe, making a line on the races and filling the spaces between rolling elements and the cage, as can be observed on Figure 2.

At this stage, the rolling elements and cage (4) are set on the lower race (3) and the thermocouples (III, IV) are mounted.

V. To complete the assembly of the upper set (UP), the retainer (7), the cover (8) and the thermocouples I and II are mounted.

VI. The lower set (LW) was previously assembled (and does not need to be reassembled for each test), and is composed by six connection pins (10 and 12) clamped to the torque cell protecting plates (9 and 13) and a torque cell (11). The lower plate (9) is mounted on the lower nonrotating shaft of the Four-Ball Machine, which applies the load to the bearing. The three lower pins (12) assure that there is no relative rotation. The three upper pins (10) are used to connect the UP to the lower set (UP $\rightarrow \mathrm{LW}$ ) preventing any relative rotation. The thermocouple $\mathrm{V}$ is permanently mounted on the protecting plate (9).

VII. The final phase is to install UP and LW into the Four-Ball Machine. First, UP is connected to the rotating shaft, and then the LW is mounted below. The conjunction will be locked by the lower shaft of the Four-Ball Machine, which is moved up to apply the load.

The bearing assembly permits to test four types of rolling bearings, including thrust ball bearings, tapered roller bearings, angular contact ball bearings and cylindrical roller thrust bearings. The geometrical limitations imposed by the Four-Ball Machine and by the bearing housing, allow a maximum bearing outer diameter of $56.0 \mathrm{~mm}$ and a maximum width of $14.3 \mathrm{~mm}$. Table I shows the different types of rolling bearings that might be tested and the corresponding dimensions and references. Depending on the bearing type, items (2) and (6), shown in Figure 1, must be replaced.

\section{Operation}

In operation, the load $(\mathrm{P})$ is applied on the lower plate (12) and the rotational speed (n) is transmitted to the shaft adapter (6), which is connected to the drive shaft of the machine (see Figure 1). The 
Table I. Types of rolling bearings that can be tested in the modified Four-Ball Machine.

\begin{tabular}{|c|c|c|c|c|c|}
\hline \multicolumn{3}{|c|}{ Dimensions } & \multirow{2}{*}{ 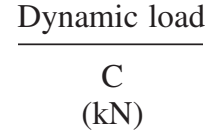 } & \multirow{2}{*}{$\begin{array}{c}\frac{\text { Limit speed }}{(\mathrm{rpm})} \\
\end{array}$} & \multirow[t]{2}{*}{ Reference } \\
\hline $\begin{array}{l}\mathrm{d} \\
(\mathrm{mm})\end{array}$ & $\underset{(\mathrm{mm})}{\mathrm{D}}$ & $\underset{(\mathrm{mm})}{\mathrm{H}}$ & & & \\
\hline \multicolumn{6}{|c|}{ Thrust ball bearings } \\
\hline 17 & 30 & 9 & 11.14 & 12000 & 51103 \\
\hline 35 & 52 & 12 & 19.90 & 7500 & 51107 \\
\hline \multicolumn{6}{|c|}{ Cylindrical roller thrust bearings } \\
\hline 17 & 28 & 9 & 11.20 & 8500 & $81102 \mathrm{TN}$ \\
\hline 35 & 52 & 12 & 29.00 & 5600 & $81107 \mathrm{TN}$ \\
\hline \multicolumn{6}{|c|}{ Angular contact ball bearings } \\
\hline 17 & 40 & 12 & 11.00 & 22000 & 7203 \\
\hline 20 & 47 & 14 & 13.30 & 18000 & 7204 \\
\hline \multicolumn{6}{|c|}{ Tapper roller bearings } \\
\hline 15 & 42 & 14,25 & 22.40 & 18000 & $30302 \mathrm{~J} 2$ \\
\hline 17 & 40 & 13,25 & 19.00 & 18000 & $30203 \mathrm{~J} 2$ \\
\hline
\end{tabular}

rotating motion is conducted through the upper race (5) to the rolling elements and cage assembly (4). The motion generates the bearing internal friction torque, which is transmitted through the lower race (3) to the bearing house (1), to the upper plate (9) and to the torque cell (11), which are all clamped together.

During the test, the rolling bearing assembly is submitted to continuous forced air convection by two fans, having $38 \mathrm{~mm}$ in diameter and running at $2000 \mathrm{rpm}$, evacuating the heat generated during bearing operation.

\section{Torque cell}

In order to preserve the torque cell and to simplify the mounting/dismounting operations, the torque cell is positioned between two circular steel plates (see Figure 1).

A piezoelectric torque cell KISTLER ${ }^{\circledR}$ 9339A, whose characteristics are shown in Table II, was selected to measure the bearing internal friction torque. The piezoelectric sensors ensure high accuracy measurements even when the friction torque generated in the bearing is very small compared to the measurement range available.

When a mechanical excitation is applied to the torque cell, the piezoelectric crystals change the electrical current. The current variation is very small and, thus, must be augmented and conditioned using an amplifier KISTLER ${ }^{\circledR}$ 5015A. The output signal is displayed and registered by the virtual instrument running in a computer.

The main restriction of the piezoelectric sensors is the undesirable changes of the output signal, called drift. ${ }^{7}$ This phenomenon happens as the result of two variable parameters: the temperature gradient and the measurement time. To avoid the drift effects in the measurements, a specified testing and measuring procedure has been developed. 
Table II. Technical characteristics of the torque cell.

\begin{tabular}{lll}
\hline Reaction Torque Sensor - KISTLER $®($ Type 9339A) & \\
\hline Measuring range & $\mathrm{N} \mathrm{m}$ & -10 to +10 \\
Overload & $\mathrm{N} \mathrm{m}$ & $-12 /+12$ \\
Sensitivity & $\mathrm{pC} / \mathrm{N} \mathrm{m}$ & $\approx-460$ \\
Tensile/compression force, max. & $\mathrm{kN}$ & $-5 /+12$ \\
Side force, max. & $\mathrm{kN}$ & 1.5 \\
Bending moment & $\mathrm{N} \mathrm{m}$ & 15 \\
Operating temperatures & ${ }^{\circ} \mathrm{C}$ & -40 to +120 \\
\hline
\end{tabular}

\section{Thermocouples}

Seven $\boldsymbol{K}$ type thermocouples with measurement range among $-40^{\circ} \mathrm{C}$ and $200^{\circ} \mathrm{C}$ and sensibility of $41 \mu \mathrm{V}{ }^{\circ} \mathrm{C}^{-1}$ are used to monitor the bearing operating temperatures. All thermocouples are positioned in strategic locations in order to measure the lubricant and bearing housing temperatures, so that the lubricant viscosity and the heat evacuated through the bearing housing can be calculated with reasonable precision. Two of these thermocouples (VI and VII) are used to record the temperatures of the air flow surrounding the bearing house and the room temperature, respectively.

\section{Software}

The developed virtual instrument was based on a LabView ${ }^{\circledR}$ platform to operate, to monitor and to control the test system. This software works in a Pentium 4 with $2.8 \mathrm{GHz}$ and $1 \mathrm{~GB}$ of RAM. The user interface is shown in the Figure 3.

\section{TEST PROCEDURE}

The test procedure is constrained by several factors, in particular, the operating limits of the Four-Ball Machine and the torque cell characteristics. ${ }^{7}$ The operating conditions imposed by the Four-Ball Machine allow tests with axial load and rotational speed up to $7000 \mathrm{~N}$ and $5500 \mathrm{rpm}$, respectively.

The drift effect from the torque cell, as described before, requires short periods of time (120 s) under stabilized temperatures $\left( \pm 2^{\circ} \mathrm{C}\right)$ to make the torque measurements.

After a visual inspection of the assembly in the Four-Ball Machine, the test is ready to start and the following procedure was used.

- For grease tests and before starting each test, a running-in period is always carried out, with an axial load of $1000 \mathrm{~N}$ and rotational speed varying from $100 \mathrm{rpm}$ to $2000 \mathrm{rpm}$ during $5 \mathrm{~min}$ to accommodate the grease.

- With the machine in off position, the desired load is applied (in the example $7000 \mathrm{~N}$ ) and the rotational speed set to the required value (100 rpm, for example); the fans are turned on to submit the rolling bearing assembly to a continuous forced air convection.

- Turn on the machine and run the software to start the data acquisition. The operating temperatures rise continuously until stabilization is reached. 


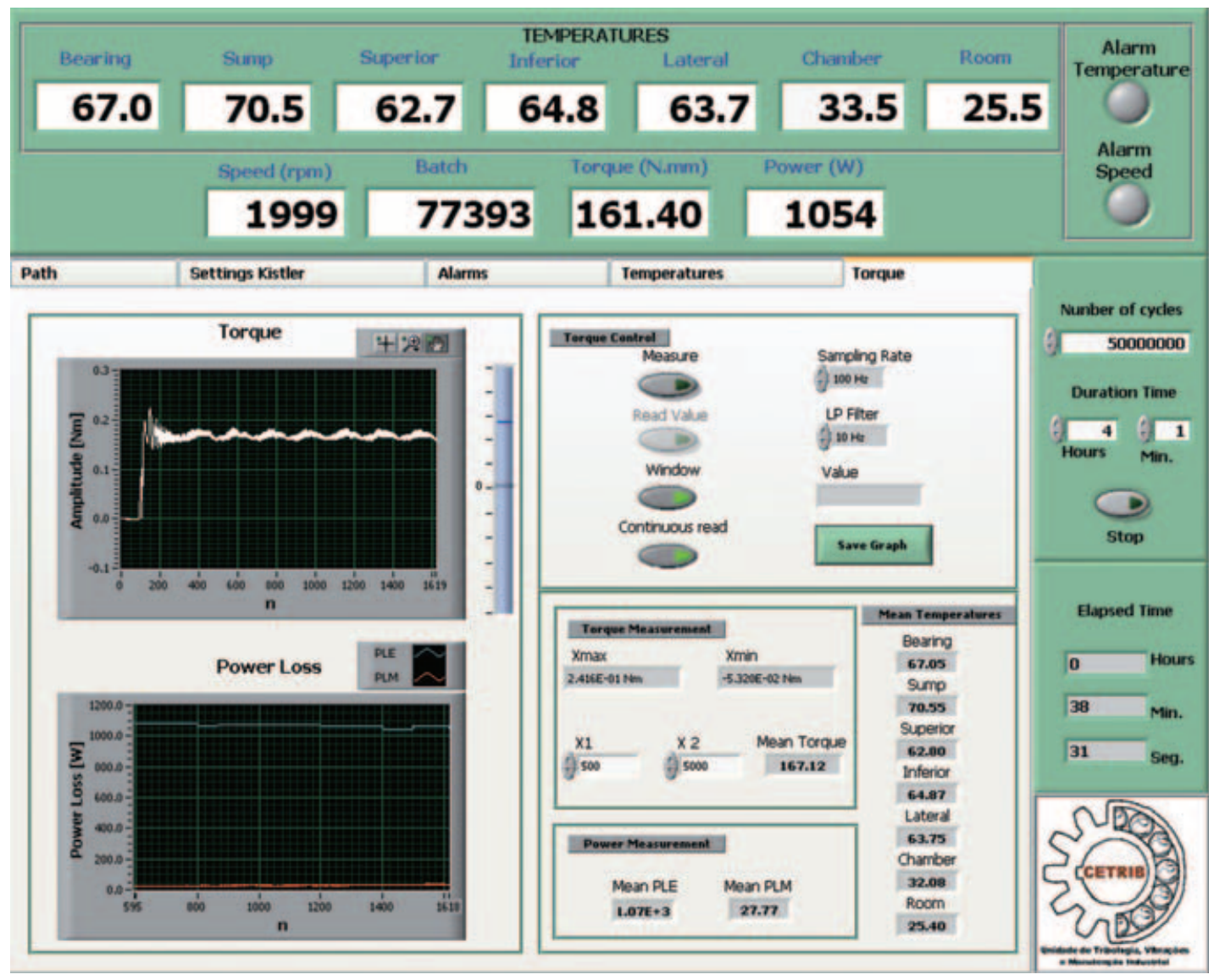

Figure 3. User LabView ${ }^{\circledR}$ interface to operate, to monitor and to control the system.

- When the temperatures are stabilized, the machine is turned off and immediately restarted again together with the torque measurement.

- After the torque measurement (120 s), maintain the rotational speed on and wait until the temperatures stabilize.

- Stages IV and V are repeated three times to get three measurements of the friction torque in the same conditions.

To measure the friction torque for other rotational speeds, the procedures described above should be repeated for each desired rotational speed. One extra procedure is taken when the friction torque is to be known at different rotational speeds: the tests should be always conducted from the lowest to the highest rotational speeds.

The friction torque value (for each rotational speed and load) is the average value of the three measurements taken during the 30th to 90th seconds from the period of $120 \mathrm{~s}$. This is because in the first $30 \mathrm{~s}$, there is a transition from the starting torque to the operating friction torque, and in the last $30 \mathrm{~s}$, sometimes, a slight drift effect is noticed. 


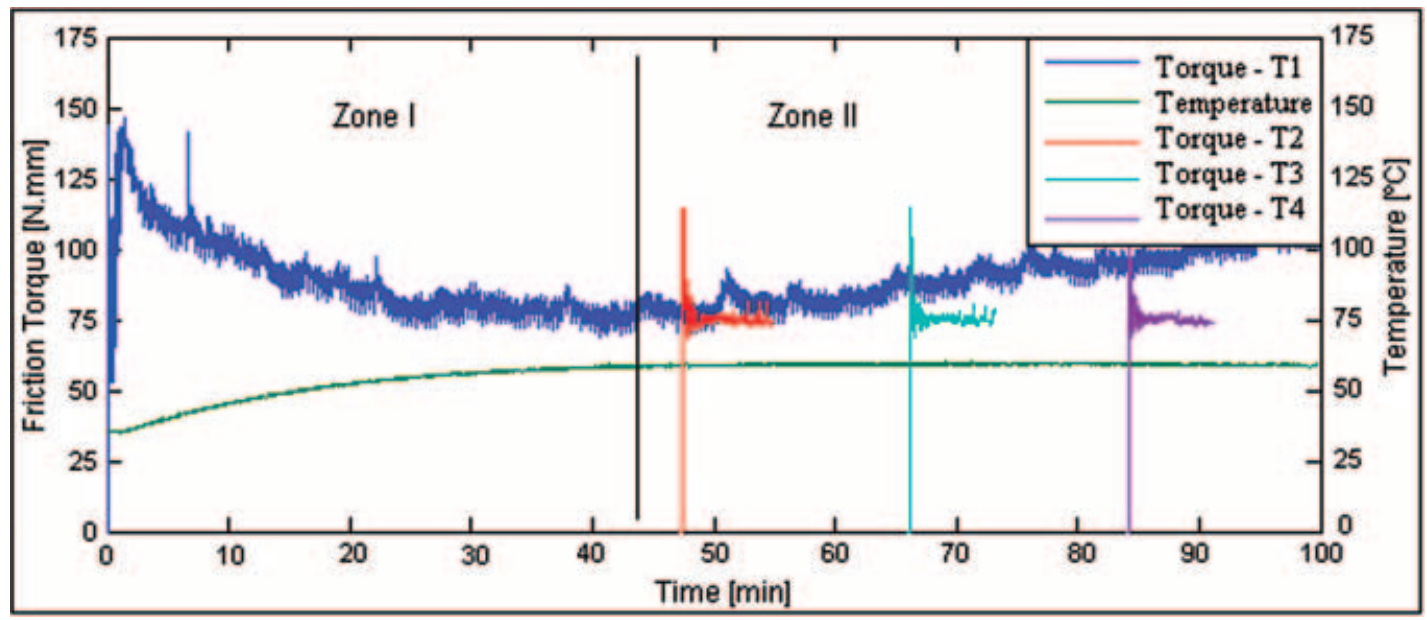

Figure 4. Friction torque and lubricant temperature (51107 Thrust Ball Bearing, $n=1500 \mathrm{rpm}$, $\mathrm{Fa}=5000 \mathrm{~N})$.

The drift effect is graphically represented in Figure 4, which shows the friction torque and operating temperature measured during a test of a 51107 thrust ball bearing, lubricated with mineral based grease under axial load of $5000 \mathrm{~N}$ and for a rotational speed of $1500 \mathrm{rpm}$.

The drift effect is clearly understood when torque curve T1 (continuous measure of friction torque and temperature during $100 \mathrm{~min}$ ) is compared with torque curves T2, T3 and T4 (obtained using the procedure mentioned above). The torque measurement $\mathrm{T} 1$ is severely affected by the thermal drift in Zone I (torque decrease due to temperature increase), and the temporal drift in Zone II (torque increase with time at constant operating temperature). The output signal variation is not linear and not reproducible from test to test, so it cannot be eliminated in a systematic or automatic way.

When using piezoelectric torque cells, the torque should be measured during short periods of time at a stabilized temperature, as in the procedure implemented. In this way, the differences between the measured values, for the same operating conditions, are very small (see Figure 4).

At the end of each test, lubricant samples can be obtained and analysed through ferrographic techniques to quantify and evaluate the wear occurred in the rolling bearing.

\section{Torque measurement repeatability}

During each test with a given lubricant (see paragraph 4), that is, at constant speed, constant load and constant temperature, the torque was recorded three times, showing very high repetitiveness, as presented in Table III.

The maximum differences between the measured torque values were $12.6 \%$ in the case of the grease base oils (BO-MG1 and BO-EG2) and 3\% in the case of the fully formulated greases (MG1 and EG2). The average values of those differences were $6.7 \%$ in the case of the base oils and $1.5 \%$ in the case of the greases. The values of the rolling bearing speed presented in parenthesis on Table III are related to the rotational speed at which the maximum difference was detected. 
Table III. Average and maximum errors for measured torque values (axial load 7000 N, rotational speed 100 to $5500 \mathrm{rpm})$.

\begin{tabular}{lcccc}
\hline Lubricant & MG1 & BO-MG1 & EG2 & BO-EG2 \\
\hline $\begin{array}{l}\text { Maximum difference [\%] @ rotational } \\
\text { speed [rpm] }\end{array}$ & $2.86 @ 350$ & $7.54 @ 2000$ & $2.94 @ 5500$ & $12.60 @ 5500$ \\
$\begin{array}{l}\text { Average difference [\%] } \\
\begin{array}{l}\text { Maximum difference [N mm] @ } \\
\text { rotational speed [rpm] }\end{array}\end{array}$ & 1.37 & 4.69 & 1.40 & 6.70 \\
Average difference [N mm] & 1.89 & $19.86 @ 350$ & $4.28 @ 350$ & $16.15 @ 350$ \\
\hline
\end{tabular}

\section{Test repeatability}

The tests performed at $1000 \mathrm{rpm}$ and $2000 \mathrm{rpm}$ were repeated three times using a new thrust rolling bearing and fresh lubricant and the corresponding results showed a very good repetitiveness. Table IV presents the statistical analysis of the torque measurements in each test, at each speed.

In general, the amplitude $(\bar{R})$ of the torque measurements was smaller in the case of the bearings lubricated with fully formulated greases than in the case of those lubricated with the corresponding base oils. It can also be observed that the amplitude of the torque measurements was higher in the tests performed at $1000 \mathrm{rpm}$, except for the case of the bearings lubricated with bio-grease EG2 where the opposite trend occurred.

In all tests, the standard deviation of the torque measurements was very similar and almost independent of the lubricant nature, of the lubricant type and of the rotational speed.

\section{TESTED LUBRICANTS}

As a demonstration of the rolling bearing test capacity using the modified Four-Ball Machine, two fully formulated greases, MG1 and the EG2, and the corresponding base oils, BO-MG1 and BO-EG2, were tested. MG1 is a commercial mineral based grease and lithium thickener and EG2 grease is formulated with ester base oil and thickened with lithium, calcium and polyurea. The physical characteristics of the tested greases are presented in Table V.

\section{EXPERIMENTAL RESULTS}

Figures 5 and 6 present the bearing friction torque and operating temperature versus the rolling bearing speed, respectively. The axial load was constant and equal to $7000 \mathrm{~N}$ and the bearing speed was in the range $100 \mathrm{rpm}-5500 \mathrm{rpm}$. The tests were performed with 51107 Thrust Ball Bearings.

Figure 5 shows that the mineral lubricants (MG1 and BO-MG1) always generated higher bearing torques than the ester biodegradable lubricants (EG2 and BO-EG2), for the same operating conditions. As an example of those differences, Figure 5 shows that for a speed of $1000 \mathrm{rpm}$ and an axial load of $7000 \mathrm{~N}$, grease MG1 generated a bearing torque of $176 \mathrm{~N} \mathrm{~mm}$, while grease EG2 generated a bearing torque of $148 \mathrm{~N} \mathrm{~mm}$, that is, $28 \mathrm{~N} \mathrm{~mm}$ less. For the same operating conditions, BO-MG1 generated an average torque of $228 \mathrm{~N} \mathrm{~mm}$, while BO-EG2 generated an average torque of $154 \mathrm{~N} \mathrm{~mm}$, that is, $74 \mathrm{~N} \mathrm{~mm}$ less. 
Table IV. Statistical parameters for measured torque values in three different tests - repetitiveness (axial load $7000 \mathrm{~N}$, rotational speed 1000 and $2000 \mathrm{rpm}$ ).

\begin{tabular}{|c|c|c|c|c|c|c|c|}
\hline \multirow[b]{2}{*}{ Tests } & \multicolumn{3}{|c|}{ Torque measured $(\mathrm{N} \mathrm{mm})$} & \multicolumn{4}{|c|}{ Statistical parameters } \\
\hline & 1 st & 2nd & $3 \mathrm{rd}$ & Average $[\bar{x}]$ & Amplitude $[\bar{R}]$ & Stan & rd deviation $[\sigma]$ \\
\hline \multicolumn{4}{|c|}{ Lubricant: MG1 } & \multicolumn{4}{|c|}{ Bearing speed: $1000 \mathrm{rpm}$} \\
\hline 1 & 166.8 & 173.7 & 163.7 & 168.1 & 9.95 & & 5.10 \\
\hline 2 & 177.4 & 172.2 & 176.5 & 175.4 & 5.14 & & 2.74 \\
\hline \multirow[t]{3}{*}{3} & 167.0 & 170.0 & 157.0 & 164.7 & 13.00 & & 6.81 \\
\hline & - & - & - & $\bar{x}=169.4$ & $\bar{R}=9.36$ & & $\sigma=5.47$ \\
\hline & \multicolumn{3}{|c|}{ Lubricant: MG1 } & & \multicolumn{3}{|c|}{ Bearing speed: 2000 rpm } \\
\hline 1 & 154.5 & 157.0 & 160.8 & 157.4 & 6.31 & & 3.18 \\
\hline 2 & 165.0 & 152.0 & 164.0 & 160.3 & 13.00 & & 7.23 \\
\hline \multirow[t]{3}{*}{3} & 153.0 & 146.0 & 147.0 & 148.7 & 7.00 & & 3.79 \\
\hline & - & - & - & $\bar{x}=155.5$ & $\bar{R}=8.77$ & & $\sigma=6.07$ \\
\hline & \multicolumn{3}{|c|}{ Lubricant: EG2 } & & \multicolumn{3}{|c|}{ Bearing Speed: 1000 rpm } \\
\hline 1 & 147.2 & 151.8 & 150.2 & 149.7 & 4.57 & & 2.32 \\
\hline 2 & 146.1 & 156.0 & 154.0 & 152.0 & 9.92 & & 5.25 \\
\hline \multirow[t]{3}{*}{3} & 147.5 & 156.0 & 156.5 & 153.3 & 9.00 & & 5.06 \\
\hline & - & - & - & $\bar{x}=151.7$ & $\bar{R}=7.83$ & & $\sigma=1.82$ \\
\hline & \multicolumn{3}{|c|}{ Lubricant: EG2 } & & \multicolumn{3}{|c|}{ Bearing Speed: 2000 rpm } \\
\hline 1 & 129.2 & 130.6 & 126.5 & 128.8 & 4.17 & & 2.11 \\
\hline 2 & 135.1 & 133.9 & 141.0 & 136.7 & 7.16 & & 3.83 \\
\hline \multirow[t]{3}{*}{3} & 135.0 & 133.0 & 119.0 & 129.0 & 16.00 & & 8.72 \\
\hline & - & - & - & $\bar{x}=131.5$ & $\bar{R}=9.11$ & & $\sigma=4.49$ \\
\hline & \multicolumn{4}{|c|}{ Lubricant: BO-MG1 } & \multicolumn{3}{|c|}{ Bearing Speed: $1000 \mathrm{rpm}$} \\
\hline 1 & 244.3 & 225.5 & 213.5 & 227.8 & 30.85 & & 15.55 \\
\hline 2 & 228.5 & 222.8 & 224.7 & 225.3 & 5.76 & & 2.93 \\
\hline \multirow[t]{3}{*}{3} & 240.5 & 215.3 & 214.0 & 223.3 & 26.50 & & 14.93 \\
\hline & - & - & - & $\bar{x}=225.5$ & $\bar{R}=21.04$ & & $\sigma=2.25$ \\
\hline & \multicolumn{4}{|c|}{ Lubricant: BO-MG1 } & \multicolumn{3}{|c|}{ Bearing Speed: 2000 rpm } \\
\hline 1 & 171.5 & 161.4 & 157.0 & 163.3 & 14.49 & & 7.43 \\
\hline 2 & 178.5 & 178.1 & 166.4 & 174.4 & 12.08 & & 6.85 \\
\hline \multirow[t]{3}{*}{3} & 174.9 & 179.3 & 169.6 & 174.6 & 9.70 & & 4.86 \\
\hline & - & - & - & $\bar{x}=170.8$ & $\bar{R}=12.09$ & & $\sigma=6.45$ \\
\hline & \multicolumn{3}{|c|}{ Lubricant: BO-EG2 } & & \multicolumn{3}{|c|}{ Bearing Speed: 1000 rpm } \\
\hline 1 & 148.7 & 163.0 & 149.8 & 153.8 & 14.37 & & 8.00 \\
\hline 2 & 151.4 & 158.7 & 144.6 & 151.6 & 14.12 & & 7.06 \\
\hline \multirow[t]{3}{*}{3} & 167.3 & 167.7 & 141.2 & 158.7 & 26.52 & & 15.20 \\
\hline & - & - & - & $\bar{x}=154.7$ & $\bar{R}=18.34$ & & $\sigma=3.65$ \\
\hline & Lubr & t: BO-E & & & Bearing Speed: 200 & $\mathrm{pm}$ & \\
\hline 1 & 147.3 & 143.9 & 141.6 & 144.2 & 5.77 & & 2.90 \\
\hline 2 & 133.8 & 148.4 & 147.0 & 143.3 & 14.53 & & 8.18 \\
\hline 3 & 130.8 & 145.0 & 138.4 & 138.1 & 14.16 & & 7.09 \\
\hline & - & - & - & $\bar{x}=141.9$ & $\bar{R}=11.49$ & & $\sigma=3.32$ \\
\hline
\end{tabular}


Table V. Physical characteristics of the lubricant greases.

\begin{tabular}{lcc}
\hline Grease designation & MG1 & EG2 \\
\hline Base oil & Mineral & Ester \\
Biodegradability (\%) & - & 60 \\
Toxicity (\%) & - & $>45$ \\
Viscosity grade (ISO VG) & 220 & 166 \\
Base oil viscosity $40^{\circ} \mathrm{C}\left(\mathrm{mm}^{2} \mathrm{~s}^{-1}\right)$ & 230 & 91.8 \\
Base oil viscosity $100^{\circ} \mathrm{C}\left(\mathrm{mm}^{2} \mathrm{~s}^{-1}\right)$ & 17.5 & 14.5 \\
LP@60 $60^{\circ} \mathrm{C} 10^{-9}(\mathrm{lubricant}$ parameter) & 1.770 & 0.623 \\
NLGI number $(\mathrm{DIN} 518181)$ & 2 & 2 \\
Dropping point $\left({ }^{\circ} \mathrm{C}\right)$ & 185 & $>181$ \\
Thickener & $\mathrm{Li}$ & $\mathrm{Li} / \mathrm{Ca}-\mathrm{Polyurea}$ \\
Operating temperature $\left({ }^{\circ} \mathrm{C}\right)$ & $-20 ;+130$ & $-30 ;+120$ \\
\hline
\end{tabular}

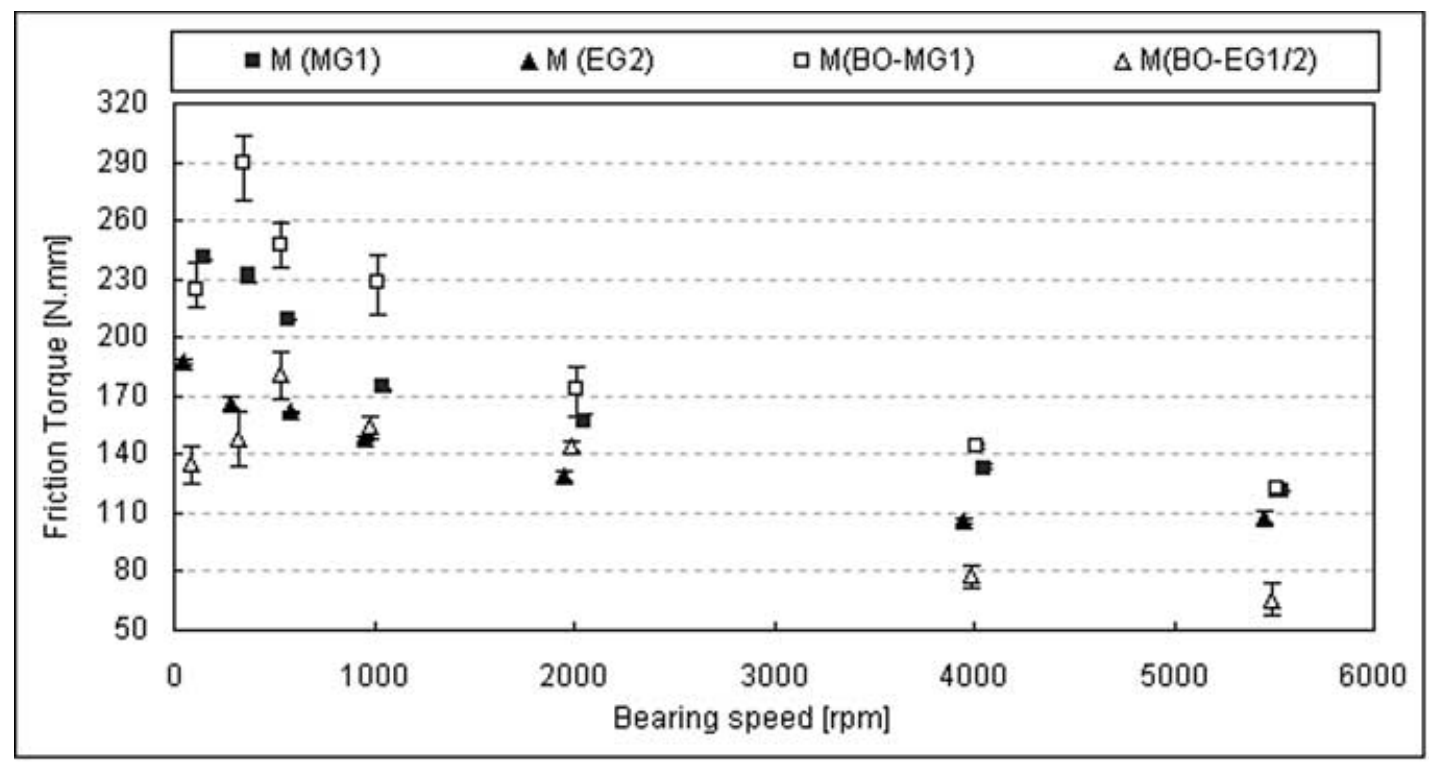

Figure 5. Bearing friction torque for different bearing speeds (axial load 7000N).

At low rotational speed, the greases generated higher bearing torques than the corresponding base oils. Such behaviour was observed with the mineral lubricants at $100 \mathrm{rpm}$ and with the ester-based lubricants below $350 \mathrm{rpm}$ (see Figure 5).

At higher speeds $(n>100 \mathrm{rpm})$, the mineral grease MG1 always generated lower bearing torques than the corresponding base oil BO-MG1, whatever the rotational speed of the thrust bearing. The difference between the bearing torques generated by these two lubricants decreased as the rotational speed increased, almost disappearing at $5500 \mathrm{rpm}$.

In the case of the ester-based lubricants, the behaviour is different. Between $500 \mathrm{rpm}$ and $2000 \mathrm{rpm}$, the bearing torque generated by the ester base oil BO-EG2 is slightly higher than the bearing torque 


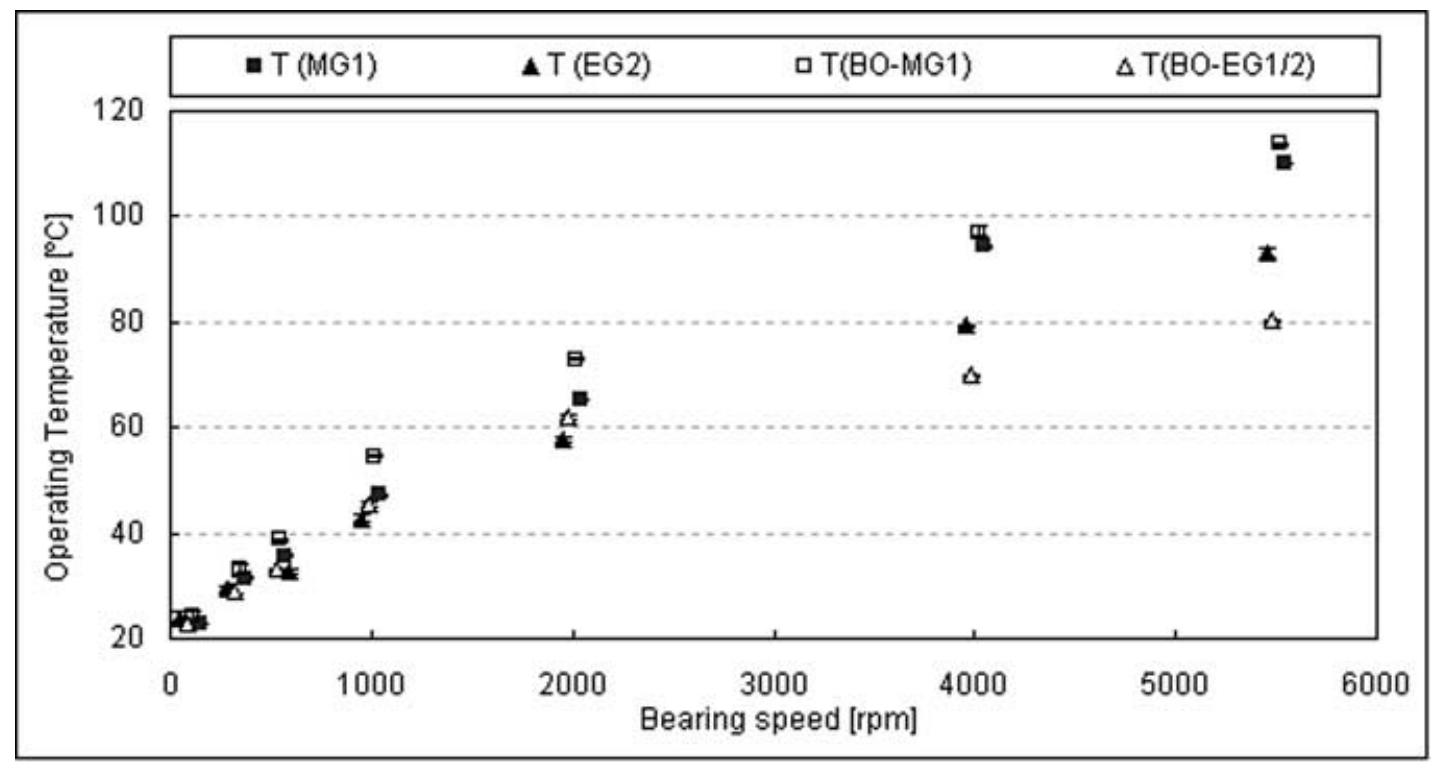

Figure 6. Bearing operating temperature for different rotational speeds.

generated by the grease EG2; however, at $4000 \mathrm{rpm}$ and $5500 \mathrm{rpm}$, the bearing friction torque generated by the base oil is significantly smaller than that generated by the grease.

Figure 5 also shows the maximum and minimum values associated with each torque measurement. As mentioned above, the repetitiveness of the torque measurements was very good, mainly in the case of the tests performed with fully formulated greases.

In general, the 51107 thrust ball bearing generates very small friction torques, since the maximum value measured in all tests was $300 \mathrm{~N} \mathrm{~mm}$. Nevertheless, the piezoelectric torque sensor, although being able to measure torques between -10 and $+10 \mathrm{~N} \mathrm{~m}$, was able to measure accurately very small torques, which is one of the major advantages of the piezoelectric sensors.

Figure 6 shows that the mineral lubricants (MG1 and BO-MG1) always generated higher bearing operating temperatures than the ester biodegradable lubricants (EG2 and BO-EG2), for the same operating conditions. At $1000 \mathrm{rpm}$ and for an axial load of $7000 \mathrm{~N}$, the bearing temperatures were $47^{\circ} \mathrm{C}$ and $43^{\circ} \mathrm{C}$ when lubricated with MG1 and EG2 greases, and $55^{\circ} \mathrm{C}$ and $45^{\circ} \mathrm{C}$ when lubricated with BO-MG1 and BO-EG2 base oils, respectively.

Figure 6 also shows the excellent repeatability of the bearing operating temperature measurements, since the differences observed between the results obtained in tests performed with the same lubricant and under the same operating conditions was always less then $2^{\circ} \mathrm{C}$.

\section{DISCUSSION}

Figure 5 shows the friction torque versus the rotational speed. The total friction torque presented the sum of four physical sources: rolling, sliding, seal and drag torque losses. ${ }^{8}$ In the case of the 51107 
thrust ball bearing tested only the rolling and sliding friction torques are considered, since seal and drag torques are not significant.

The rolling friction torque is mainly dependent on the rotating speed and on the viscosity of the grease base oil. Thus, it is not surprising that, at constant speed (e.g. $500 \mathrm{rpm})$ the friction generated by the mineral grease (MG1) is significantly higher than that generated by the ester grease (EG2), since the base oil viscosity of MG1 (305.5 cSt @ 35.6 $\left.6^{\circ} \mathrm{C}\right)$ is significantly higher than that of grease EG2 (126.2 cSt @ 32. $\left.8^{\circ} \mathrm{C}\right)$.

In the case of the 51107 thrust ball bearing, the rolling friction torque decreases and the operating temperature increases when the operating speed increases, whatever the grease considered (see Figure 5). This is not surprising, since the tests where run without temperature control, although fresh air, at room temperature, was insufflated into the test chamber in order to improve heat evacuation through forced convection. When speed increases the operating temperature rises and the drop in base oil viscosity is much more important than the increase in rotating speed, explaining why the bearing friction torque decreases continuously with speed increase.

At $4000 \mathrm{rpm}$, the operating temperatures of grease EG2 and MG1 are $79.2^{\circ} \mathrm{C}$ and $94.5^{\circ} \mathrm{C}$, respectively, as shown in Figure 6. At those operating temperatures and speed, the viscosity of the corresponding base oils are similar, $24.1 \mathrm{cSt}$ and $20.6 \mathrm{cSt}$, but the ester-based grease (EG2) generates lower friction torque than the mineral grease (MG1), as presented in Figure 5. This behaviour indicates that the nature of the base oil (and thus of grease formulation) affects the sliding friction torque inside the thrust ball bearing.

At $1000 \mathrm{rpm}$, the friction torque and the operating temperature generated by the mineral grease (MG1) and by its base oil (BO-MG1) are $176 \mathrm{~N} \mathrm{~mm} / 47^{\circ} \mathrm{C}$ and $228 \mathrm{~N} \mathrm{~mm} / 55^{\circ} \mathrm{C}$, respectively. Besides the differences in viscosity (because of the different operating temperatures) and in lubricant film generation (oil vs grease) the main difference is due to the fact that the base oil tested didn't contain additives. This result indicates that the presence of additives and their type (thus, grease formulation) affects the sliding torque inside the thrust ball bearing.

Figures 5 and 6 show that the repetitiveness of the bearing friction torques and of the operating bearing temperatures was always better with greases than with the corresponding base oils (see also Table IV). The main reason for such behaviour is not related to the type of lubricant (grease or oil) but to the presence of additives. Greases MG1 and EG2 are fully formulated lubricants while base oils BO-MG1 and BO-EG2 did not contain additives, in particular, extreme-pressure and anti-wear additives.

For the same operating conditions and constant surrounding temperature, a higher bearing friction torque generates higher power loss, higher heat evacuation to the surrounding neighbourhood, and, consequently higher bearing operating temperature. Figures 5 and 6 clearly show that higher bearing friction torques always correspond to higher operating bearing temperatures, showing that the correlation between these two parameters is excellent.

In Figure 7, the total bearing friction torque is plotted against the rotational speed for a spherical roller bearing lubricated with high-viscosity oil, in deep lubrication (oil bath). The three components of the bearing torque (rolling, sliding and drag) are also presented. The total frictional torque shown in Figure 7 and the torque measurements presented in Figure 5 have the same behaviour and are in close agreement with the latest bearing friction model developed by SKF. ${ }^{8}$

One of the main features of the SKF model is the separation of the true physical friction sources in the rolling bearing: rolling, sliding, seals and drag losses, allowing a better understanding of the friction in rolling bearings and helping to save energy and optimize bearing performance. 


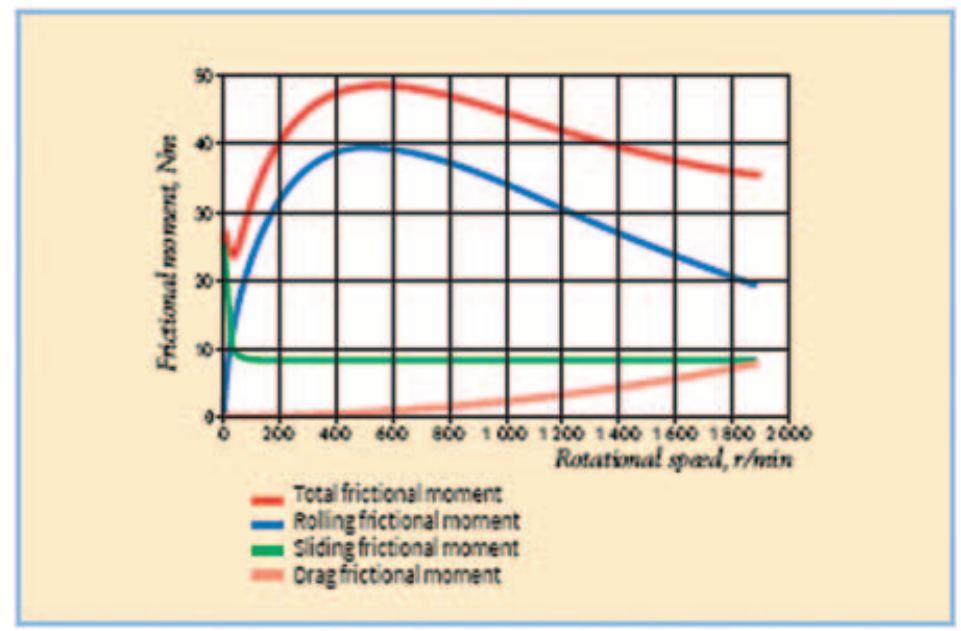

Figure 7. Frictional moment versus rolling speed at constant temperature. ${ }^{8}$

\section{CONCLUSIONS}

- Rolling bearing tests may be conveniently performed using the rolling bearing assembly developed and manufactured for the Four-Ball Machine, allowing to test several different types of rolling bearings submitted to axial loads up to $7000 \mathrm{~N}$ and rotational speeds up to $6000 \mathrm{rpm}$.

- The torque sensor and signal amplifier, the thermocouples and the LabView ${ }^{\circledR}$ based software allow an adequate monitoring of the rolling bearing tests, a precise measurement of the bearing friction torque and of the bearing operating temperature.

- The testing procedure ensures a convenient repetitiveness of the bearing friction torque and bearing operating temperature measurements.

- The experimental results of the tests performed with 51107 thrust ball bearings, lubricated with fully formulated greases and the corresponding base oils, indicate an excellent correlation between the bearing friction torque and the bearing operating temperatures.

\section{ACKNOWLEDGEMENTS}

The authors wish to thank the Fundação para a Ciência e Tecnologia from the Portuguese Administration for the financial support given to this work through the project 'Low friction, biodegradable and low toxicity greases for rolling bearings', through research contract PTDC/EME.PME/72641/2006.

\section{REFERENCES}

1. SKF General Catalogue 6000 EN, pg 88, November 2005.

2. Ellis EG. Testing grease for rolling bearings. Industrial Lubrication and Tribology 1970; 22:14-18. 
3. Kalin M, Vižintin J. Rolling bearings and lubricants testing machine, CTD-ML1. Journal of Mechanical Engineering 1997; 43(5-6):239-247.

4. Cann PM. Grease lubrication of rolling element bearings - role of the grease thickener. Lubrication Science 2007; 19: 183-196.

5. Couronné I, Mazuyer D, Vergne P, Truong-Dinh N, Girodin D. Effects of grease composition and structure on film thickness in rolling contact. Tribology Transactions 2002; 46(1):31-36.

6. Lugt PM. A review on greases lubrication in rolling bearings. Tribology Transaction 2009; 52:470-480.

7. Kistler Instruments AG. Reaction Torque Sensor $9339^{\circ}$ and Charge Meter 5015A Instruction Manual, 2008 Edition.

8. Guillermo ME. Using a friction model as an engineering toll. Evolution SKF 2006; 2:27-30. 